\title{
Patterns of oxygen supply in embryo masses of brachyuran crabs throughout development: the effect of oxygen availability and chemical cues in determining female brooding behavior
}

\author{
Miriam Fernández*, Luis Miguel Pardo**, Juan Antonio Baeza*** \\ Estación Costera de Investigaciones Marinas and Center for Advanced Studies in Ecology and Biodiversity, Departamento \\ de Ecología, Facultad de Ciencias Biológicas, Pontificia Universidad Católica, Alameda 340, Casilla 114-D, Santiago, Chile
}

\begin{abstract}
Different patterns of variation in oxygen availability throughout development have been observed in embryo masses of brooding species of marine invertebrates, and this variation seems to be related to the strategy to solve the oxygen limitation problem of the broods. As yet, little is known about patterns of oxygen availability and female brooding behavior (abdominal flapping) throughout development in brachyuran crabs, and about which factors trigger abdominal flapping. These issues were experimentally studied in $2 \mathrm{crab}$ species of similar body size (Cancer setosus and Homalaspis plana). In addition, oxygen consumption of crab embryos and 2 potential factors that could trigger changes in female brooding behavior were studied (oxygen partial pressure and nonidentified chemical cues produced by the embryos). Optic fibers were used to monitor oxygen partial pressure $\left(\mathrm{pO}_{2}\right)$ in the embryo mass as female behavior was videotaped; optic fibers do not affect female behavior. Microchambers were used to determine oxygen consumption of the embryos. Females carrying early stage embryos connected to containers with water under different treatments were used to evaluate the effect of $\mathrm{pO}_{2}$ and chemical cues on female behavior. A cyclic pattern in $\mathrm{pO}_{2}$ was detected in masses of early stage embryos and constant high $\mathrm{pO}_{2}$ for late stages. As changes in $\mathrm{pO}_{2}$ in the embryo mass occurred, an increase in oxygen demand by the embryos and an increase in abdominal flapping frequency were detected in both species. Abdominal flapping seems to be affected by low $\mathrm{pO}_{2}$ in the embryo mass and also by the presence of late stage embryos. These results support previous findings suggesting that oxygen provision to embryos seems to be a critical factor determining parental investment across taxa of marine invertebrates.
\end{abstract}

KEY WORDS: Brachyuran crabs $\cdot$ Brooding $\cdot$ Marine invertebrates $\cdot$ Oxygen

Resale or republication not permitted without written consent of the publisher

\section{INTRODUCTION}

Brooding in marine systems is restricted to species with small body size (Strathmann \& Strathmann 1982),

\footnotetext{
*Email: mfernand@genes.bio.puc.cl

Present addresses:

${ }^{* *}$ Université Laval, Departament du Biologie, GIROQ, Québec G1K7P4, Canada

*** Department of Biology, The University of Louisiana at Lafayette, PO Box 4245, Lafayette, Louisiana 70504-2451, USA
}

probably because of constraints in oxygen supply to embryo masses (Strathmann \& Chaffee 1984, Strathmann \& Strathmann 1989). Supporting this hypothesis, strong oxygen gradients have been found in gelatinous egg masses (Cohen \& Strathmann 1996). Even in taxa that show an exception to the association between brooding and small body size, such as brachyuran crabs, oxygen availability in the center of the embryo mass is lower than at the periphery (Naylor et al. 1999a, Fernández et al. 2000). The physical constraints of brooding affect the degree of parental investment 
and care provided to the offspring. Among the species that brood, investment in parental care could be in the form of gel (which helps oxygen diffusion into the egg mass; Chaffee \& Strathmann 1984, Strathmann \& Strathmann 1995, Cohen \& Strathmann 1996) or active ventilation (which increases oxygen availability; Baeza \& Fernández 2002). In contrast, broadcasting appears to be the simplest and cheapest way to ventilate large numbers of eggs (Strathmann \& Chaffee 1984). The physical constraints of brooding can also have important life history consequences among marine invertebrates (Strathmann \& Strathmann 1982) as well as implications on management and conservation plans, since differences in early development affect potential for dispersal, population dynamics, and extinction and speciation rates (Valentine \& Jablonski 1983).

Oxygen availability in the center of egg masses of marine invertebrates varies over time, but in a different fashion depending on the brooding strategies. Flow regime and light affect daily variations in oxygen availability in gelatinous egg masses (Cohen \& Strathmann 1996), while the increase in oxygen demand by the embryos throughout development generates a dramatic decrease in oxygen availability in the center of the egg mass from early to late development (Chaffee \& Strathmann 1984, Booth 1995, Cohen \& Strathmann 1996). Temporal variation in oxygen availability in the center of the embryo mass of brachyuran crabs shows a different pattern. First, oxygen availability in the center of embryo masses varies over smaller temporal scales (minutes), at least during early development of the embryos (Fernández et al. 2000). Secondly, oxygen availability in the center of the embryo mass increases throughout development, in spite of the increase in oxygen demand of the embryos, at least in the 2 species of Cancer that have been studied to date (Naylor et al. 1999a, Baeza \& Fernández 2002). The main cause of the differences in temporal variations in oxygen availability between crabs and gelatinous egg masses seems to be the ventilation of the embryos (abdominal flapping) by female crabs, which increases exchange of oxygen rich water (Baeza \& Fernández 2002). In Cancer species, the frequency of abdominal flapping changes throughout embryo development (Baeza \& Fernández 2002). It is not yet clear how consistent this pattern of oxygen provision throughout development is among brachyuran crabs, nor which factors trigger abdominal flapping. To evaluate the consistency of the findings reported for Cancer species, patterns of oxygen availability, frequency of abdominal flapping and oxygen consumption by embryos throughout development were studied in 2 crab species of similar body size (Cancer setosus and Homalaspis plana). Two potential factors that could trigger changes in frequency of abdominal flapping, oxygen partial pressure and non-identified chemical (water-borne) cues produced by the embryos, were also analyzed in 1 of the 2 species ( $H$. plana). Here, the broad term brooding behavior was used to refer to abdominal flapping or female ventilation of the embryos, and low or high oxygen availability was used to refer to low or high oxygen partial pressure, which correlates with the concentration of unbound dissolved oxygen.

\section{MATERIALS AND METHODS}

Samples. Two crab species belonging to different families were selected: Cancridae: Cancer setosus (Molina 1782), and Xanthidae: Homalaspis plana (Milne-Edwards 1834). Both species exhibit similar ranges of distribution (Retamal 1981) and body size, brood during winter and early spring, and support commercial fisheries (Fernández \& Castilla 1997). Crabs were collected by SCUBA in El Quisco $\left(33^{\circ} 23^{\prime} \mathrm{S}\right.$, $\left.71^{\circ} 42^{\prime} \mathrm{W}\right)$, Las Cruces $\left(33^{\circ} 29^{\prime} \mathrm{S}, 71^{\circ} 38^{\prime} \mathrm{W}\right)$ and Coquimbo $\left(29^{\circ} 58^{\prime} \mathrm{S}, 71^{\circ} 22^{\prime} \mathrm{W}\right)$, Chile. After collection, females were measured (carapace width; CW) and maintained in holding tanks $(3 \mathrm{~m}$ in diameter, $0.5 \mathrm{~m}$ deep) with circulating seawater at $14^{\circ} \mathrm{C}$ and constant aeration. In the holding tanks, crabs were fed ad libitum on fresh mussels (Choromytilus chorus). Size of brooding females ranged between 97.5 and $136.7 \mathrm{~mm}$ for C. setosus $(\bar{x}=124.1 \mathrm{~mm} \pm 10.1)$ and between 80.3 and $129.5 \mathrm{~mm}$ for $H$. plana $(\bar{x}=100.9 \pm 13.7)$. Size of control (non-brooding) females ranged between 94.5 and $125.3 \mathrm{~mm}$ for C. setosus, and between 88.9 and $129.1 \mathrm{~mm}$ for $H$. plana. Mean diameter of the embryo mass was $56.14 \mathrm{~mm} \pm 7.69(\mathrm{n}=66)$ in $H$. plana and $59.7 \mathrm{~mm} \pm 7.99(\mathrm{n}=66)$ in $C$. setosus. The developmental stage of the embryos was determined in each female used in the experiments (Wear 1974). Three stages were determined: Stage I: gastrulation (some cells without vitellium of the animal pole); Stage II: nauplius (first appendages just appearing); and Stage III: metanauplius (heart pumping, ocular pigment and chromatophores present). All experiments and calibrations of oxygen consumption experiments were conducted at constant, average temperature in the study area $\left(14^{\circ} \mathrm{C}\right)$.

Oxygen availability in the center of the embryo mass of brooding females. To determine patterns of oxygen availability in the center of the embryo mass of brooding females carrying embryos in Stages I (early), II (intermediate) and III (late), laboratory experiments were conducted. Optic fibers (Microoptodes Presens) with a tip diameter between 20 and $50 \mu \mathrm{m}$ were used to continuously monitor oxygen partial pressure in the center of the embryo mass (Microx I; Holst et al. 1997, Klimant et al. 1997). A small hole $(<1 \mathrm{~mm})$ was drilled 
into the abdomen $(1 / 2$ of the VI segment) of brooding females and a plastic tube (of variable length depending on embryo mass diameter) was inserted and fixed to the abdomen. The microoptode was inserted into the tube after calibration ( $0 \%$ air saturation: solution saturated with $\mathrm{Na}_{2} \mathrm{SO}_{3} ; 100 \%$ air saturation: aerated water from the tank where the experiment was conducted). Both the tube and the microoptode were fixed to the carapace using cyanoacrylate glue and dental wax. The tip of the optic fiber reached $2 \mathrm{~mm}$ outside the catheter and was in contact with the embryos. After the microoptode was fixed, females were placed in the experimental tank $(25 \times 25 \times 25 \mathrm{~cm})$ filled with a $5 \mathrm{~cm}$ layer of shell hash and rocks, and unfiltered seawater. Constant aeration was maintained during the whole experimental period. After $1 \mathrm{~h}$, oxygen availability $(\mathrm{mm} \mathrm{Hg})$ in the center of the embryo mass was monitored continuously for $24 \mathrm{~h}$ and recorded in a computer every $5 \mathrm{~s}$. Using the $24 \mathrm{~h}$ records, the percentage of time that the embryos from the center of the mass were exposed to 2 levels of oxygen partial pressure $\left(\mathrm{pO}_{2}\right.$; low $<39.7$ and high $>79.4 \mathrm{~mm} \mathrm{Hg}$ ) was calculated for each female. These 2 categories of $\mathrm{pO}_{2}$ were selected considering: (1) the level of $\mathrm{pO}_{2}$ below which embryo oxygen consumption is always affected $(<39.7 \mathrm{~mm}$ $\mathrm{Hg}) ;$ and (2) the level of $\mathrm{pO}_{2}$ above which oxygen consumption is not affected (>79.4 $\mathrm{mm} \mathrm{Hg}$; Naylor et al. 1999a, Fernández et al. 2000, Baeza \& Fernández 2002). Four replicates were conducted for each species and each developmental stage. Two-way ANOVAs were used to test for differences in the mean proportion of time exposure of the embryos to each category of $\mathrm{pO}_{2}$ between species and stage. Data were transformed in 1 case $(>79.4 \mathrm{~mm} \mathrm{Hg})$ in order to meet the assumptions of the ANOVA model. A SNK test was used for post hoc comparisons (Zar 1996).

In addition, autocorrelation analyses were conducted to detect the presence of cycles in $\mathrm{pO}_{2}$. When cycles were detected (all females carrying embryos in Stages I and II but not in Stage III, see 'Results'), the data were fitted to Fourier series (minimum-square method) and a periodogram was obtained. Stationary time series were also obtained. Spectral analyses were conducted to determine the dominant frequency in each time series (Chatfield 1989). In each replicate, the 5 largest periodogram peaks (frequency domain) were recorded, transformed to period and expressed in minutes needed to complete 1 full cycle (Chatfield 1989). A 2-way ANOVA (fixed factors) was used to test for differences in the mean time needed to complete a $\mathrm{pO}_{2}$ cycle between species and stages (only females carrying embryos in Stages I and II showed cycles and were compared).

Abdominal flapping. To assess patterns of abdominal flapping in relation to embryo developmental stages, females were videotaped as $\mathrm{pO}_{2}$ in the center of the embryo mass was being measured (both instruments were set to the same time). Thus, the same number of replicates as above were used for this experiment. A 12:12 h day:night cycle was simulated with white and red lights, respectively, using an automatic switch system. Female behavior was videotaped using a Sony time-lapse video (SVT-3000) and a Pelco vigilance camera. Recording of female behavior began $1 \mathrm{~h}$ after the microoptode was introduced into the embryo mass. Two video blocks ( $2 \mathrm{~h}$ each) were randomly analyzed for each experimental female, one during the day and another during the night. Day and night time blocks were included in order to account for differences in female brooding behavior during a $24 \mathrm{~h}$ cycle as part of the variance in the data. Abdominal flapping and resting time (defined as having no apparent activity) were recorded. Non-brooding females were also videotaped and used as a control group in order to assess if the total time that females spent flapping the abdomen or resting was related to the presence of the embryo mass. The percentage of the total time spent flapping the abdomen (or resting) was estimated and compared between species and developmental stages using a 2-way ANOVA. Data were transformed when the assumptions of the model were not met (Table 1). SNK post hoc comparisons were conducted to determine differences among levels in each factor of the ANOVA.

To assess the effect of the optic fiber on the behavior of brooding females, the percentage of time spent performing 2 behaviors, i.e. abdominal flapping by brooding females and walking by brooding and non-

Table 1. Results of the 2-way ANOVAs conducted to test for differences in the mean percentage of time allocated to resting and abdominal flapping between species (Cancer setosus and Homalaspis plana) and among female condition (non-brooding females and brooding females carrying embryos at Stages I, II and III). Transformations are indicated between parentheses. Mean values (and SD) are reported in Fig. 2C,D. ${ }^{* *}$ Statistical significant differences were detected

\begin{tabular}{|c|c|c|c|c|c|c|c|c|c|}
\hline \multirow[t]{2}{*}{ Variable } & \multicolumn{3}{|c|}{ Factor: species } & \multicolumn{3}{|c|}{ Factor: developmental stage } & \multicolumn{3}{|c|}{ Interaction term } \\
\hline & $F$ & $\mathrm{df}$ & $\mathrm{p}$ & F & $\mathrm{df}$ & $p$ & $F$ & $\mathrm{df}$ & $\mathrm{p}$ \\
\hline Resting $(1 / x)$ & 1.49 & 1,24 & 0.23 & 6.45 & 3,24 & $0.002^{* *}$ & 2.49 & 3,24 & 0.085 \\
\hline Abdomen flapping (ln) & 0.002 & 1,24 & 0.97 & 17.16 & 3,24 & $<0.00001^{* *}$ & 1.082 & 3,24 & 0.37 \\
\hline
\end{tabular}


Table 2. Results of the 2-way ANOVAs conducted to test for the effect of the optic fiber on female behavior (abdominal flapping and walking) between developmental stages (early and late embryos) for the 2 experimental conditions used (with and without optic fiber). The analysis was conducted for both species (Cancer setosus and Homalaspis plana). ${ }^{* *}$ Statistical significant differences were detected

\begin{tabular}{|c|c|c|c|}
\hline Factor & $F$ & df & $\mathrm{p}$ \\
\hline \multicolumn{4}{|c|}{ (A) Cancer setosus: abdominal flapping (natural log transformation) } \\
\hline Stage of development of the embryos & 13.69 & 1 & $0.0018^{* *}$ \\
\hline Experimental condition & 2.67 & 1 & 0.1207 \\
\hline Interaction & 0.193 & 1 & 0.671 \\
\hline Error & & 17 & \\
\hline \multicolumn{4}{|c|}{ (B) Cancer setosus: walking (data were not transformed) } \\
\hline Stage of development of the embryos & 0.97 & 1 & 0.347 \\
\hline Experimental condition & 0.004 & 1 & 0.948 \\
\hline Interaction & 1.75 & 1 & 0.203 \\
\hline Error & & 17 & \\
\hline \multicolumn{4}{|c|}{ (C) Homalaspis plana: abdominal flapping (natural log transformation) } \\
\hline Stage of development of the embryos & 29.6 & 1 & $0.0001^{* *}$ \\
\hline Experimental condition & 3.98 & 1 & 0.063 \\
\hline Interaction & 0.31 & 1 & 0.59 \\
\hline Error & & 16 & \\
\hline \multicolumn{4}{|c|}{ (D) Homalaspis plana: walking (data were not transformed) } \\
\hline Stage of development of the embryos & 1.098 & 1 & 0.3113 \\
\hline Experimental condition & 0.001 & 1 & 0.971 \\
\hline Interaction & 0.17 & 1 & 0.691 \\
\hline Error & & 16 & \\
\hline
\end{tabular}

brooding females, was compared. The experiment was conducted using females carrying early (Stage I) and late (Stage III) embryos $(n=4)$, because of the contrast in their behavior (Baeza \& Fernández 2002). Female behavior was recorded using the same experimental set-up described above. A 2-way ANOVA was used to compare the mean percentage of time spent performing a behavior (abdominal flapping and walking) between females with or without the optic fiber and between developmental stages (Zar 1996). Abdominal flapping data were transformed to meet the assumptions of the model (Table 2).

Oxygen consumption of crab embryos. Laboratory experiments were conducted to determine oxygen consumption of embryos of both species at $2 \mathrm{pO}_{2}$ (<39.7 and $>79.4 \mathrm{~mm} \mathrm{Hg}$ ) and 3 stages of development (I, II and III). Oxygen consumption of the embryos was recorded under constant temperature, using a double walled, closed microchamber filled with $2 \mathrm{ml}$ of filtered $(0.2 \mu \mathrm{m})$ seawater (with added antibiotic). After calibration, a blank (seawater without embryos) was used in order to determine the presence of bacteria that could affect oxygen consumption estimates. Another blank was repeated at the end of the experiment. Oxygen consumption of the embryos was measured only when oxygen consumption of the blank was 0 . A small number of embryos were removed from the periphery of the embryo mass of brooding females and placed on a fine grid in the microchamber. Water was stirred inside the chamber using a stir bar to avoid oxygen depletion near the embryos when unstirred (Naylor et al. 1997); the grid avoided direct contact between the stir bar and the embryos. Oxygen depletion was monitored continuously with oxygen electrodes (Eschweiler M200; measure range: 0 to $760 \mathrm{~mm} \mathrm{Hg}$; resolution $0.1 \mathrm{~mm} \mathrm{Hg}$ ) for variable times depending on the developmental stage of the embryos until oxygen was depleted to $30 \mathrm{~mm} \mathrm{Hg}$. At the end of the experimental period, the embryos were weighed (wet weight). A minimum of 5 measurements was conducted for each stage and $\mathrm{pO}_{2}$ level. Oxygen consumption per unit of time and weight was estimated for each developmental stage, species and $\mathrm{pO}_{2}$, and compared using a 3-way ANOVA. Data were transformed (natural log) in order to meet the assumptions of the model.

Effect of $\mathrm{pO}_{2}$ and chemical cues on female brooding behavior. A laboratory experiment was conducted in order to evaluate possible factors that could trigger female brooding behavior. As stated above, brooding behavior was used to refer to abdominal flapping or female ventilation of the embryos (Baeza \& Fernández 2002). A second, small hole $(<1 \mathrm{~mm})$ drilled into the abdomen was used to insert a plastic tube (of variable length depending on embryo mass diameter), which was used to direct water maintained under the different treatments into the embryo mass of brooding 
females using a peristaltic pump. Treatments resulted from the combination of the different levels of the 2 factors analyzed: embryo stage and $\mathrm{pO}_{2}$. Water containing early (Stage I) and late (Stage III) embryos or no embryos was used as levels for the embryo stage factor. For oxygen partial pressure, 2 levels were used: seawater maintained at high $(158.8 \mathrm{~mm} \mathrm{Hg})$ and low $(15.9 \mathrm{~mm} \mathrm{Hg}) \mathrm{pO}_{2}$ i these were used because of the patterns of oxygen availability observed in the center of the embryo mass (Fernández et al. 2000, Baeza \& Fernández 2002). Thus, treatments were: (1) low oxygenno embryos; (2) low oxygen-early embryos; (3) low oxygen-late embryos; (4) high oxygen-no embryos; (5) high oxygen-early embryos; and (6) high oxygenlate embryos. Water was pumped into the embryo mass of brooding females (carrying early stage embryos) at a flow rate of $20 \mathrm{ml} \mathrm{min}{ }^{-1}$ from 11 containers filled with seawater under the different treatments. In the treatments where embryos were added, $20 \mathrm{~g}$ of embryos were used per container. The experiment was started at 20:00 h. During the experimental period, $\mathrm{pO}_{2}$ and female behavior were monitored simultaneously (as explained above), beginning $1 \mathrm{~h}$ before treatments were applied. Treatments were randomly applied to each crab for $1 \mathrm{~h}$ each, after which no further water was pumped to experimental females, but $\mathrm{pO}_{2}$ and brooding behavior continued to be monitored (control). To incorporate the control (no water pumped into the embryo mass) into the analysis while maintaining the factorial experimental design, the difference between each treatment and the control for each female was estimated. Thus, the response variable used in the 2-way ANOVAs was the difference between the treatment and the control. Data were not transformed since the assumptions of the model were met.

\section{RESULTS}

\section{Oxygen availability in the center of the embryo mass of brooding females}

$\mathrm{pO}_{2}$ in the center of the embryo mass showed a distinctive pattern for each developmental stage and this pattern was consistent in both species (Fig. 1). A cyclic pattern of $\mathrm{pO}_{2}$ was detected in Stages I and II, and relatively constant oxygen availability was found for Stage III. The results shown in Fig. 1 are for 1 female in each case and stage (different females were used for each stage), but the patterns were very consistent in all females studied (Fig. 2A,B). In Cancer setosus, the peaks appeared shaved off on the left side and asymmetric compared with the symmetric peaks of Homalaspis plana. The mean time used to complete a full cycle of $\mathrm{pO}_{2}$ in the center of the embryo mass was not significantly different between species (ANOVA: $F=0.13, \mathrm{df}=1,11, \mathrm{p}=0.73$ ), but varied with embryo developmental stage (ANOVA: $F=17.92, \mathrm{df}=1,11$, $p=0.001$; Fig. 2A). The interaction term was not significant (ANOVA: $F=0.17, \mathrm{df}=1,11, \mathrm{p}=0.69$ ). The mean frequency of $\mathrm{pO}_{2}$ cycles was significantly higher in females carrying embryos in Stage II than I $(p<0.05)$; females carrying embryos in Stage III were not included in the analysis because no cycle in $\mathrm{pO}_{2}$ was found (Fig. 2A). Oxygen availability never reached low $\mathrm{pO}_{2}$ in masses of Stage III embryos.

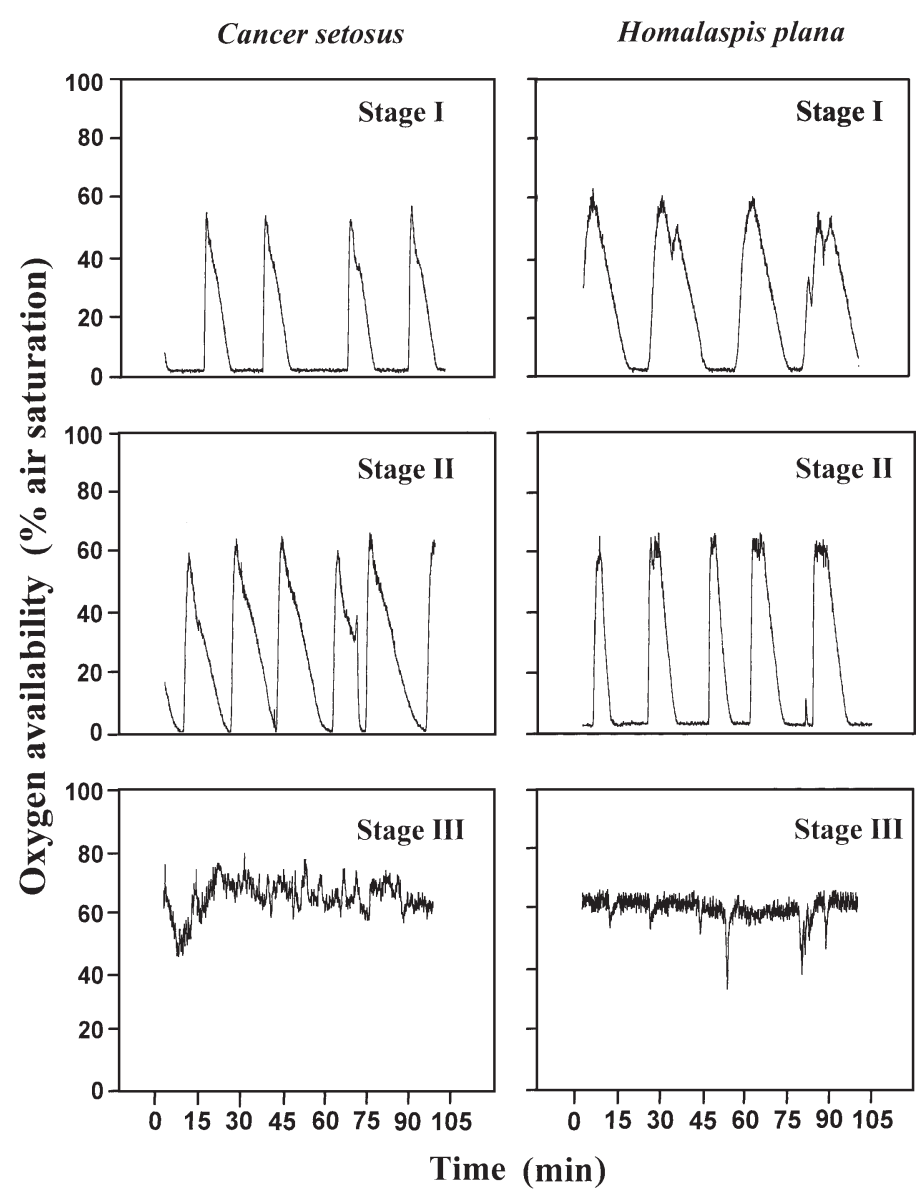

Fig. 1. Patterns of oxygen partial pressure in the center of the embryo mass of Cancer setosus (left) and Homalaspis plana (right) for early (I), intermediate (II) and late (III) stages of embryo development. The patterns shown here are for 1 female of each species and embryo developmental stage; however, these results were consistent across replicates and the summary of the information for all females analyzed is shown in Fig. 2. Fractions of the $24 \mathrm{~h}$ recording (105 $\mathrm{min}$ ) were randomly selected to depict the pattern of $\mathrm{pO}_{2}$ of both species and the 3 stages of development 
Table 3. Results of the 2-way ANOVAs conducted to test for differences in the mean percentage of time that embryos were exposed to each level of $\mathrm{pO}_{2}$, between species (Cancer setosus and Homalaspis plana) and among the 3 developmental stages (brooding females carrying embryos at Stages I, II, and III). Independent ANOVAs were conducted for the 2 percentages of time that embryos were exposed to each range of $\mathrm{pO}_{2}(<39.7$ and $>79.4 \mathrm{~mm} \mathrm{Hg})$. Mean values (and SD) are shown in Fig. 2B. In both cases, significant differences among developmental stages were found and all levels were significantly different (I < II $<$ III; $\mathrm{p}<0.05) .{ }^{* *}$ Statistical significant differences were detected

\begin{tabular}{|c|c|c|c|c|c|c|c|c|c|}
\hline \multirow{2}{*}{ Variable } & \multicolumn{3}{|c|}{ Factor: species } & \multicolumn{3}{|c|}{ Factor: developmental stage } & \multicolumn{3}{|c|}{ Interaction term } \\
\hline & $F$ & $\mathrm{df}$ & $\mathrm{p}$ & $F$ & $\mathrm{df}$ & $\mathrm{p}$ & $F$ & df & $\mathrm{p}$ \\
\hline$\%$ time spent at $\mathrm{pO}_{2}<39.7 \mathrm{~mm} \mathrm{Hg}$ (sq rt) & 8.34 & 1,18 & $0.0098^{* *}$ & 160.86 & 2,18 & $<0.00001^{* *}$ & 2.65 & 2,18 & 0.10 \\
\hline$\%$ time spent at $\mathrm{pO}_{2}>79.4 \mathrm{~mm} \mathrm{Hg}$ & 0.40 & 1,18 & 0.54 & 102.67 & 2,18 & $<0.00001^{* *}$ & 1.99 & 2,18 & 0.16 \\
\hline
\end{tabular}

Early embryos (Stage I) were exposed to low $\mathrm{pO}_{2}$ (<39.7 mm Hg) for significantly longer time periods than Stages II and III embryos ( $p<0.05$; Fig. 2B). As a consequence, late embryos (III) were exposed most of the time to high $\mathrm{pO}_{2}$ (>79.4 $\mathrm{mm} \mathrm{Hg}$; $<0.05$; Fig. 2B). No differences between species were found at high $\mathrm{pO}_{2}$, but embryos of Homalaspis plana were exposed to $\mathrm{pO}_{2}<39.7 \mathrm{~mm} \mathrm{Hg}$ a higher percentage of time than embryos of Cancer setosus (Table 3, Fig. 2B). The interaction term was not significant in both cases (Table 3).
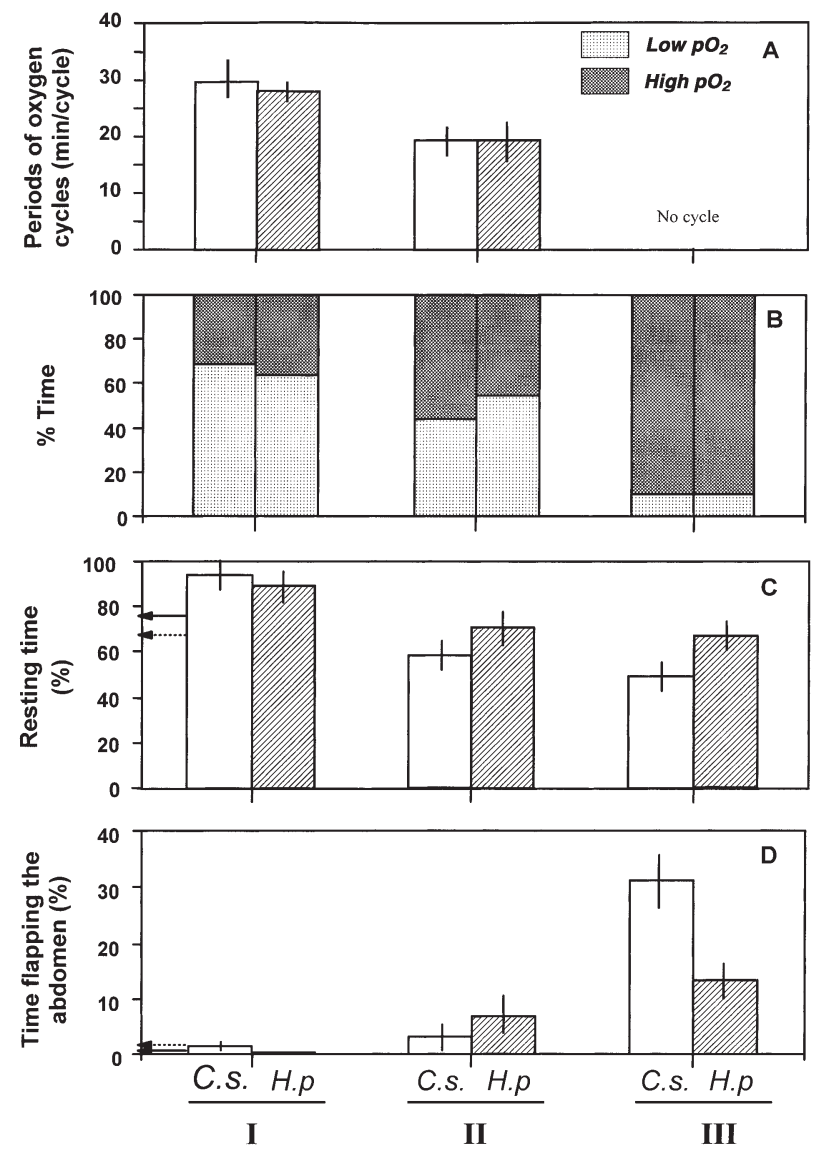

Embryonic stage

\section{Abdominal flapping}

Significant differences in the mean percentage of time that females used for abdominal flapping and resting were detected between stages of development (Table 1). No differences between species were found (Table 1). Females carrying early embryos (I) and control females spent most of the time resting; in both species the mean percentage of time assigned to resting decreased as embryos developed (Stages II and III, $\mathrm{p}<0.05$; Fig. 2C). The opposite pattern was found for the mean percentage of time spent flapping the abdomen (Table 1, Fig. 2D); again no differences were found between control and brooding females carrying early embryos. The mean percentage of time spent flapping the abdomen increased for females carrying embryos in Stage II, and was highest for females carrying Stage III embryos (Table 1, Fig. 2D; $\mathrm{p}<0.05$ ). Abdominal flapping occurred when females were in a standing position; one or more flapping events (movement backwards and forwards of the abdomen) may occur each time that females adopt the standing position. During flapping, the entire embryo mass can be shaken using the pleopods.

Fig. 2. (A) Periods of oxygen partial pressure (mm Hg) cycles as detected by the microoptodes in the center of the embryo mass of ovigerous females of Cancer setosus (C.S., left) and Homalaspis plana (H.p., right) for early (I), intermediate (II) and late (III) stages of embryo development. The same pattern for the bars and symbols are used for each species in the rest of the panels; (B) mean percentage of the total time $(24 \mathrm{~h})$ that low $(<39.7 \mathrm{~mm} \mathrm{Hg})$ and high (>79.4 $\mathrm{mm} \mathrm{Hg})$ oxygen partial pressures were measured in the center of the embryo masses of $C$. setosus and $H$. plana females carrying embryos at the 3 developmental stages (Stages I, II and III); (C) percentage of time (of the total time monitored) that females adopted a resting position at each stage of embryo development. The arrows indicate the mean percentage of time that control females (no embryos) were inactive (solid line: C. setosus; broken line: $H$. plana). (D) Percentage of time that females spent flapping the abdomen at each stage of embryo development. The arrows indicate the mean percentage of time that control females (no embryos) flapped the abdomen. Horizontal bars always indicate SE 


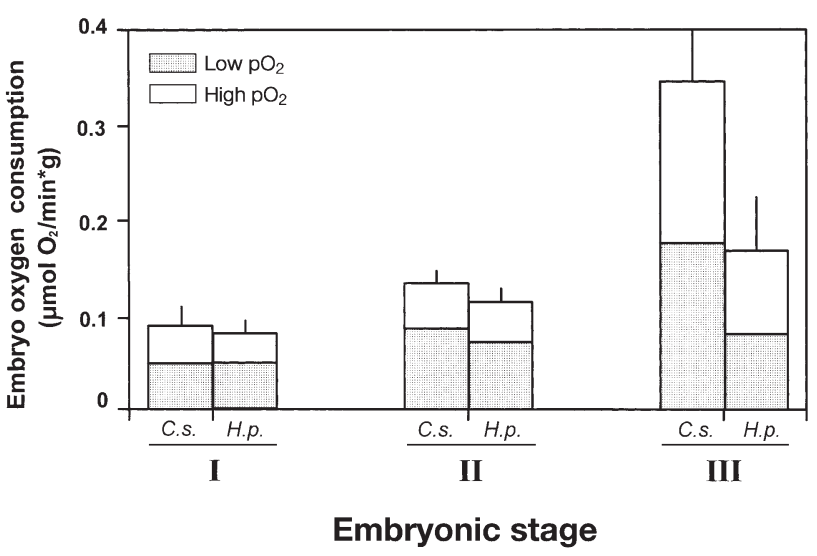

Fig. 3. Mean oxygen consumption of embryos (per g wet weight) of Cancer setosus (C.S., left) and Homalaspis plana (H.p., right) at each developmental stage and level of oxygen partial pressure. Vertical lines indicate SE

The experimental condition (use of the optic fiber) did not affect female behavior (Table 2). The mean frequency of abdominal flapping increased with embryo development, as shown above; however, the mean time spent performing this behavior was not affected but the presence of the optic fiber was (Table 2). The non-brooding behavior analyzed (walking) was not affected by the optic fiber either, and did not change throughout development (Table 2).

\section{Oxygen consumption of crab embryos}

Mean oxygen consumption of crab embryos was significantly different among embryonic developmental stages (ANOVA: $F=10.79, \mathrm{df}=2,52, \mathrm{p}=0.0001$ ), between species (ANOVA: $F=9.14, \mathrm{df}=1,52, \mathrm{p}=$ 0.0039 ) and between $\mathrm{pO}_{2}$ levels (ANOVA: $F=11.17$, $\mathrm{df}=1,52, \mathrm{p}=0.0015$; Fig. 3). None of the interaction terms were significant $(p>0.061)$. Oxygen consumption was higher for embryos of Cancer setosus than Homalaspis plana, increased significantly from Stage I to II, and from Stage II to III, and was higher at $\mathrm{pO}_{2}>$ $79.4 \mathrm{~mm} \mathrm{Hg}$ than at $\mathrm{pO}_{2}<39.7 \mathrm{~mm} \mathrm{Hg}$ (Fig. 3).

\section{Effect of $\mathrm{pO}_{2}$ and chemical cues on female brooding behavior}

The mean difference in $\mathrm{pO}_{2}$ between treatments and control was significantly higher at high $\mathrm{pO}_{2}$ treatments (ANOVA: $F=66.67, \mathrm{df}=1,34, \mathrm{p}<0.00001$; Fig. $4 \mathrm{~A}$ ). No differences in $\mathrm{pO}_{2}$ in the embryo mass among embryo stage treatments were found (ANOVA: $F=0.871$, $\mathrm{df}=2,34, \mathrm{p}=0.871 ;$ Fig. $4 \mathrm{~A})$. The interaction term was not significant (ANOVA: $F=0.275$, df $=2,34, \mathrm{p}=$ 0.761 ). The main effects could not be tested for the second variable (mean difference in the frequency of abdominal flapping) since the interaction term was significant (ANOVA: $F=4.46, \mathrm{df}=1,30, \mathrm{p}=0.02$; Fig. 4B). This was due to the dramatic increase in the mean difference in frequency of abdominal flapping when the effects of high $\mathrm{pO}_{2}$ and late stage embryos were combined (Fig. 4B). Abdominal flapping frequency was lower when seawater containing no embryos or early embryos at high $\mathrm{pO}_{2}$, was pumped into the embryo mass (Fig. 4B). No differences in abdominal flapping frequency were detected among embryo stage treatments maintained at low $\mathrm{pO}_{2}$ and late embryos maintained at high $\mathrm{pO}_{2}$ (Fig. 4B). Mean $\mathrm{pO}_{2}$ and abdominal flapping frequency per treatment are reported in Table 4.
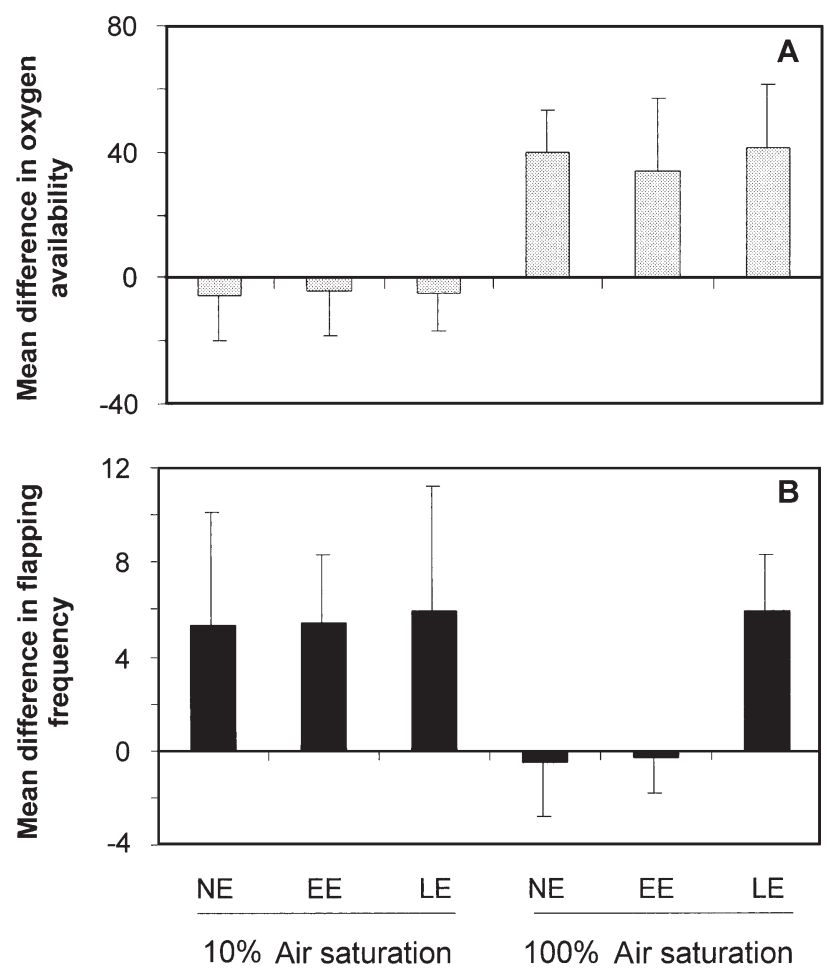

Fig. 4. (A) Mean difference in oxygen partial pressure when water containing no embryos (NE), early stage embryos (EE) or late stage embryos (LE) at low (15.9 mm Hg) or high (158.8 $\mathrm{mm} \mathrm{Hg}$ ) oxygen partial pressure was pumped into the embryo mass of females carrying early stage embryos. (B) Mean difference in abdominal flapping frequency under the same conditions. In both cases, the difference was calculated between the application of a treatment and the control situation (no water pumped into the embryo mass). Vertical lines indicate SE 
Table 4. Mean $\mathrm{pO}_{2}$ and mean frequency of abdominal flapping in the different experimental treatments: control, water containing low (or high) $\mathrm{pO}_{2}$ and no embryos, early stage embryos or late stage embryos. Water from the experimental containers under the different treatments was pumped into the embryo mass of females carrying early stage embryos. $\mathrm{SE}$ is indicated between parenthesis

\begin{tabular}{|lcc|}
\hline Treatment & $\begin{array}{c}\text { Mean oxygen } \\
\text { availability }\end{array}$ & $\begin{array}{c}\text { Mean abdominal } \\
\text { flapping }\end{array}$ \\
\hline Control & $60.60(6.25)$ & $12.2(0.60)$ \\
High $\mathrm{pO}_{2}$-no embryos & $52.95(9.00)$ & $11.8(0.92)$ \\
$\mathrm{High}_{2}$-early embryos & $54.44(8.36)$ & $11.7(0.94)$ \\
High $\mathrm{pO}_{2}$-late embryos & $52.91(7.48)$ & $18.2(1.17)$ \\
Low $\mathrm{pO}_{2}$-no embryos & $105.69(12.13)$ & $17.6(1.59)$ \\
Low $\mathrm{pO}_{2}$-early embryos & $106.86(12.51)$ & $17.7(1.92)$ \\
Low $\mathrm{pO}_{2}$-late embryos & $116.87(12.35)$ & $18.2(2.15)$ \\
\hline
\end{tabular}

\section{DISCUSSION}

The main findings of this study can be divided in 2 categories: (1) those related to the concurrent changes in patterns of oxygen availability, female behavior and oxygen demand of the embryos; and (2) those related to the identification of 2 possible factors causing female brooding behavior.

The cyclic pattern in $\mathrm{pO}_{2}$ in the embryo mass during early development is consistent with previous reports for other crab species (Fernández et al. 2000, Baeza \& Fernández 2002). The slightly different shapes of the $\mathrm{pO}_{2}$ peaks between species could be due to: (1) differences in oxygen consumption of the embryos, i.e. those of Homalaspis plana consumed less oxygen than embryos of Cancer setosus; (2) differences in the size of the embryos, i.e. those of $H$. plana are larger than embryos of $C$. setosus, so water flow through the embryo mass may vary between species (Strathmann \& Chaffee 1984); and (3) differences in alternative mechanisms of ventilation not detected here e.g. internal ventilation (Wheatly 1981, Mantel 1983, Naylor et al. 1999b). What is clear, however, is that the slight differences in the shape of the $\mathrm{pO}_{2}$ peaks did not have a major effect on the percentage of the time that the embryos were exposed to different $\mathrm{pO}_{2}$ levels.

The changes in $\mathrm{pO}_{2}$ throughout development produced differences in the total time that embryos were exposed to different $\mathrm{pO}_{2}$; early embryos spent most of the time at low $\mathrm{pO}_{2}$, while late embryos spent most of the time at high $\mathrm{pO}_{2}$. These 2 extreme ranges in $\mathrm{pO}_{2}$ could have an effect on embryo development since embryo oxygen demand was negatively affected at the same low, experimental $\mathrm{pO}_{2}$. It is interesting to note that as embryo oxygen demand increased, brooding females spent less time resting and more time flapping the abdomen. Thus, late stage embryos, which con- sume oxygen at higher rates, were never exposed to low $\mathrm{pO}_{2}$. Recently Baeza \& Fernández (2002) showed a direct link between abdominal flapping and oxygen availability in Cancer setosus, suggesting that abdominal flapping is the main behavior directed towards providing oxygen to the embryos. Results suggest that the same mechanism of oxygen provision may operate in other crab species, given the similarities found in all the species studied so far. Active embryo mass ventilation has already been suggested for Cancer pagurus as well as the importance of the standing position, abdominal flapping and pleopods in ventilation of the embryos (Naylor et al. 1999a). However, the results of this study show that brooding females ventilate the embryo mass throughout development, rather than only during late development as has previously been suggested (Naylor et al. 1999a). These observations clearly suggest that: (1) as females became more active and spent more time flapping the abdomen, the cycles in oxygen availability decreased and embryos experienced higher levels of oxygen in the center of the embryo mass; and (2) these changes in female behavior and oxygen availability corresponded to increases in oxygen demand by the embryos.

The changes in female ventilatory behavior and oxygen provision could be related to oxygen demand by the embryos. Similar changes have been found in the ventilatory behavior of female amphipods (Dick et al. 1998) and in caridean shrimps (Pandian 1994), although the changes in behavior were not accompanied by measures of oxygen conditions of the brood. The effect of oxygen limitation during embryonic development on developmental rate, survival and performance of subsequent stages is not yet well understood. Aynchronic development of inner embryos has been related to low oxygen availability in embryo masses (Chaffee \& Strathmann 1984, Strathmann \& Strathmann 1995). Severe oxygen limitation of embryos incubated in the center of the mass during early development could also be related to the high variability in post-hatching larval viability within a clutch which has been recorded for some decapods (Pandian 1970a,b, Pandian \& Katre 1972, Kunisch \& Anger 1984). Thus, changes in female behavior corresponding to increases in oxygen consumption rate may help to maintain a synchronic developmental rate within the embryo mass (see Chaffee \& Strathmann 1984, Strathmann \& Strathmann 1995) or may increase survival probability for later developmental stages.

Considering that ventilation patterns of brooding females seem to follow oxygen demands of the embryos, it can be expected that $\mathrm{pO}_{2}$ or some cue produced by the embryos (or products of embryo metabolism) could serve as a signal for brooding females to ventilate (see Forward et al. 1987, Rittschof et al. 1989, 
Saigusa 1996). Results suggest that in fact, both factors had a significant effect on abdominal flapping frequency. Low $\mathrm{pO}_{2}$ explained the increase in mean flapping frequency as compared with controls, regardless of the presence or the stage of embryos. The flapping frequency in the control treatment (no water pumped into the embryo mass) was similar to that reported for Cancer setosus (Baeza \& Fernández 2002), suggesting that the experimental manipulation (holes drilled in the abdomen) did not affect female behavior. However, $\mathrm{pO}_{2}$ in the embryo mass does not seem to be the only factor affecting female behavior since abdominal flapping frequency was affected by water containing late embryos. The compound that affected abdominal flapping frequency could be a product of embryo metabolism, increasing its concentration as metabolic rate increases during embryo development (Booth 1995, Cohen \& Strathmann 1996). A response to pheromones is also possible since chemical responses to pheromones have been detected during the hatching of crab embryos and seem to produce the same behavior (abdominal flapping; Forward et al. 1987, Rittschof et al. 1989, Saigusa 1996). The effect of this additional factor is obvious when water from late stage embryos is pumped into the embryo mass of brooding females carrying early stage embryos. Furthermore, the presence of this unknown compound could also be responsible for the negative effect in flapping frequency, when water containing no embryos or early embryos at high $\mathrm{pO}_{2}$ was pumped into the embryo mass of brooding females. We hypothesize that this same compound, at higher concentrations, may trigger the behavior adopted by females during larval hatching (Tankersley et al. 2002). The presence of 2 different factors affecting female brooding behavior is also suggested by the natural patterns of oxygen availability and flapping frequencies reported above. If $\mathrm{pO}_{2}$ was the only factor triggering female behavior, then oxygen availability should show a cyclic pattern (or at least some peaks of low $\mathrm{pO}_{2}$ ) also during late development. Biological rhythms may not be a plausible explanation for the changes in female behavioral patterns throughout development since abdominal flapping frequency in females carrying early embryos were modified experimentally.

Finally, it is important to emphasize that the results of this study support previous findings suggesting that oxygen is a limiting factor in the egg masses of several taxa of marine invertebrates. This implies that oxygen provision to the embryos may be an important factor shaping life history patterns and one of the critical factors determining parental investment among marine invertebrates. Parental investment in relation to oxygen provision to embryos may range from no investment in ventilation (broadcasting, as the simplest way to provide oxygen to a large number of embryos) to investment in extraembryonic material (Chaffee \& Strathmann 1984, Lee \& Strathmann 1998), or in active brooding behaviors that can help to provide oxygen to the embryos (Naylor et al. 1999a). Thus, patterns of oxygen provision and the adjustment of oxygen provision according to embryo demand may vary greatly among taxa. In many taxa of marine invertebrates, investment in extraembryonic material, i.e. gel that helps oxygen diffusion, can be substantial and is assigned during egg deposition (Perron 1981, Defreese \& Clark 1983). Taxa that show more active brooding behavior related to oxygen provision (e.g. brachyuran crabs: Fernández et al. 2000; octopuses: Voight \& Grehan 2000) may be able to change their energy allocation to ventilation depending on embryo demand and environmental conditions that affect oxygen consumption of the embryos (e.g. temperature; Clarke 1982). Among brachyuran crabs, investment in brooding may be substantial, especially for late stage embryos (a 2-fold increase in oxygen consumption was found in brooding females when compared to nonbrooding females; Fernández et al. 2000, Baeza \& Fernández 2002). In light of these results, the current approach to studying the investment in reproduction among marine invertebrates, i.e. ratio of reproductive biomass, gonad or egg mass weight to the mass of the parent, regardless of the mode of development of the embryos, seems not to be appropriate and may require urgent revision.

Acknowledgements. We thank Antonio Brante, Sandra Cifuentes, Patricio Manríquez, Paula Neill, Marcelo Rivadeneira, Nathaly Ruiz-Tagle and Rubén Soto, and 3 anonymous reviewers for their helpful comments. We also thank our colleagues from ECIM, especially Ivan Albornoz, for their collaboration in many different aspects of this work. Finally, we acknowledge financial support from FONDAP (O\&BM\#3Crustacean), the Volkswagen Foundation and FONDAPFONDECYT (Grant 1501-0001).

\section{LITERATURE CITED}

Baeza JA, Fernández M (2002) Active brood care in Cancer setosus (Crustacea: Decapoda): the relationship between female behaviour, embryo oxygen consumption, and the cost of brooding. Funct Ecol 16:241-251

Booth D (1995) Oxygen availability and embryonic development in sand snail egg masses. J Exp Biol 198:241-247

Chaffee C, Strathmann R (1984) Constraints on egg masses. I. Retarded development within thick egg masses. J Exp Mar Biol Ecol 84:73-83

Clarke A (1982) Temperature and embryonic development in polar marine invertebrates. Int J Invertebr Reprod 5:71-82

Chatfield C (1989) The analysis of time series. Chapman \& Hall, London

Cohen C, Strathmann R (1996) Embryos at the edge of tolerance: effects of environment and structure of egg masses on supply of oxygen to embryos. Biol Bull 190:8-15 
Defreese DE, Clark DB (1983) Analysis of reproductive energetics of Florida opistobranchia (Mollusca; Gastropoda). Int J Invertebr Reprod 6:1-10

Dick JT, Faloon SE, Elwood RW (1998) Active brood care in an amphipod: influences of embryonic development temperature and oxygen. Anim Behav 56:663-672

Fernández M, Castilla JC (1997) The Chilean artisanal stone crab (Homalaspis plana) fishery: catch trends in open access zones and the effect of management areas in Central Chile. J Shellfish Res 16(2):371-377

Fernández M, Bock C, Pörtner HO (2000) The cost of brooding in brachyuran crabs: the ignored factor in the reproduction of marine invertebrates. Ecol Lett 3:487-494

Forward RB Jr, Rittschof D, DeVries MC (1987) Peptide pheromones synchronize crustacean eggs hatching and larval release. Chem Senses 12:491-498

Holst G, Glud R, Kühl M, Klimant I (1997) A microoptode array for fine-scale measurements of oxygen distribution. Sensors and Actuators B 38/39:122-129

Klimant I, Kühl M, Glud G, Holst G (1997) Optical measurements of oxygen and temperature in microscale: strategies and biological applications. Sensors and Actuators B 38/39: 29-37

Kunisch M, Anger K (1984) Variation in development and growth rates of larval and juvenile spider crabs Hyas araneus reared in the laboratory. Mar Ecol Prog Ser 15: 293-301

Lee C, Strathmann R (1998) Scaling of gelatinous clutches: effects of sibling competition for oxygen on clutch size and parental investment per offspring. Am Nat 151:293-300

Mantel LH (1983) Internal anatomy and physiological regulation. In: Bliss DE (ed) The biology of Crustacea, Vol 5. Academic Press, New York, p 1-371

Naylor JK, Taylor EW, Bennett DB (1997) The oxygen uptake of ovigerous edible crabs (Cancer pagurus) and their eggs. Mar Freshw Behav Physiol 30:29-44

Naylor JK, Taylor EW, Bennett DB (1999a) Oxygen uptake of developing eggs of Cancer pagurus (Crustacea: Decapoda: Cancridae) and consequent behavior of ovigerous females. J Mar Biol Assoc UK 79:305-315

Naylor JK, Taylor EW, Bennett DB (1999b) Heart rate and gill ventilation in ovigerous and non-ovigerous edible crabs, Cancer pagurus: the effects of disturbance, substrate and starvation. Mar Freshw Behav Physiol 32:129-145

Pandian TJ (1970a) Ecophysiological studies on the developing eggs and embryos of the European lobster Hommarus gammarus. Mar Biol 5:153-167

Pandian TJ (1970b) Yolk utilization and hatching time in the Canadian lobster Hommarus americanus. Mar Biol 7: 249-254

Editorial responsibility: Otto Kinne (Editor),

Oldendorf/Luhe, Germany
Pandian TJ (1994) Arthropods-Crustacea. In: Adiyodi KG, Adiyodi RG (eds) Reproductive biology of invertebrates. Oxford and IBH Publishing, Kerala, p 1-165

Pandian TJ, Katre S (1972) Effect of hatching time on larval mortality and survival of the prawn Macrobrachium idea. Mar Biol 13:330-337

Perron F (1981) The partition of reproductive energy between ova and protective capsules in marine gastropods of the genus Conus. Am Nat 118:110-118

Retamal M (1981) Catálogo ilustrado de los Crustáceos Decápodos de Chile. Gayana 44:1-110

Rittschof D, Forward RB Jr, Simons DA, Reddy PA, Erickson BW (1989) Peptide analogs of the mud crab pumping pheromones: structure-function studies. Chem Senses 14: $137-148$

Saigusa M (1996) Two kinds of active factor in crab hatch water: ovigerous-hair stripping substance (OHSS) and protease. Biol Bull 191:234-240

Strathmann R, Chaffee C (1984) Constraints on eggs masses. II. Effects of spacing, size, number of eggs on ventilation of masses of embryos in jelly, adherent group, or thin-walled capsules. J Exp Mar Biol Ecol 84:85-93

Strathmann R, Strathmann M (1982) The relationships between adult size and brooding in marine invertebrates. Am Nat 119:91-101

Strathmann R, Strathmann M (1989) Evolutionary opportunities and constraints demonstrated by artificial gelatinous egg masses. In: Ryland JS, Tyler PA (eds) Reproduction, genetics and distribution of marine organisms. Olsen \& Olsen, Fredensborg, p 201-209

Strathmann R, Strathmann M (1995) Oxygen supply and limits on aggregation of embryos. J Mar Biol Assoc UK 75:413-428

Tankersley RA, Bullock TM, Forward RB, Rittschof D (2002) Larval release behaviors in the blue crab Callinectes sapidus: role of chemical cues. J Exp Mar Biol Ecol 273: $1-14$

Valentine J, Jablonski D (1983) Larval adaptations and patterns of Brachiopods diversity in time and space. Evolution 37:1052-1061

Voight JR, Grehan A (2000) Egg brooding by deep-sea octopuses in the North Pacific Ocean. Biol Bull 198:94-100

Wear RG (1974) Incubation in British Decapod Crustacea and the effects of temperature on the rate and success of embryonic development. J Mar Biol Assoc UK 54:745-762

Wheatly MG (1981) The provision of oxygen to developing eggs by female shore crabs (Carcinus maenas). J Mar Biol Assoc UK 61:117-128

Zar JH (1996) Biostatistical analysis, 3rd edn. Prentice Hall, Upper Saddle River, NJ

Submitted: December 5, 2001; Accepted: August 19, 2002

Proofs received from author(s): November 18, 2002 